\title{
DESCRIBING BREASTFEEDING PRACTICES IN NEW SOUTH WALES USING DATA FROM THE NSW CHILD HEALTH SURVEY, 2001
}

\author{
Debra Hector and Karen Webb \\ NSW Centre for Public Health Nutrition \\ University of Sydney
}

\section{Sharon Lymer \\ National Centre for Social and Economic Modelling University of Canberra}

The National Health and Medical Research Council (NHMRC) have outlined breastfeeding practices conducive to health in their Dietary Guidelines for Children and Adolescents in Australia ${ }^{1}$, including exclusive breastfeeding to about six months of age, introducing solids appropriately at around six months of age, and extending breastfeeding to at least 12 months of age (see "National Health and Medical Research Council infant feeding guidelines for health workers', page 41 in this issue). However there is little information about the extent to which population breastfeeding practices are consistent with these guidelines. There is no national monitoring system for collecting and disseminating information about breastfeeding practices in Australia. ${ }^{2}$ The Australian Bureau of Statistics (ABS) National Health Survey collects information about breastfeeding, but the information presented has not been fully aligned with the recommended national indicators (see Box 1: Recommended indicators and definitions used for monitoring breastfeeding in Australia, page 38 in this issue), or the NHMRC guidelines. Consequently, it is difficult to measure changes in breastfeeding practices in the population and to plan and target programs and services to promote breastfeeding.

The NSW Child Health Survey 2001 was the first largescale population survey conducted in NSW to generate extensive data on breastfeeding practices in a representative sample of the population. ${ }^{3}$ Prior to this survey there had been limited studies of selected hospitals and communities in NSW, using a variety of definitions, survey questions and sample frames. ${ }^{4}$ Because these surveys reported breastfeeding practices differently and calculated breastfeeding rates for infants of different ages, it has been difficult to combine results to describe the population as a whole.

This paper summarises the findings from a recently published report that described breastfeeding practices in NSW, using data collected in the NSW Child Health Survey 2001. Where possible, we have compared breastfeeding rates from the 2001 Child Health Survey with those from the 1995 ABS National Health Survey to give an indication of trends. We developed 'interim' indicators for use in the analysis of the NSW survey data that reflect the NHMRC guidelines. ${ }^{10}$ The full report, Report on breastfeeding in $N S W, 2004$, provides more detail on each of the indicators, including differences in rates between main population subgroups, and between geographic areas defined by area health service boundaries.

\section{METHOD}

The NSW Child Health Survey $2001^{3}$ used computer-assisted telephone interviews to collect information. The respondents were mothers or carers of children aged up to 12 years from households selected by list-assisted random digit dialling across the state, with a target of 500 children from each of the (then) 17 area health services in NSW. The survey component relating to breastfeeding and infant feeding practices was conducted on a subset of the main survey sample and included carers of infants and children aged 0 to 23 months at the time of the survey, a sample of 1489. Limiting the sample to the very young reduced the period over which the respondents, mainly mothers (87.7\%), had to recall their children's feeding practices, a factor shown to influence the validity of information about the timing of the introduction of breastmilk substitutes and solid foods, and the duration of exclusive and predominant breastfeeding.

The 2001 survey questions about breastfeeding were similar to those used in the 1995 National Health Survey. ${ }^{5-7}$ Both surveys were conducted before the publication of the recommended national breastfeeding indicators, ${ }^{2}$ and the data do not allow full reporting on the national indicators. For example, because consumption of water was not assessed, the prevalence and duration of exclusive breastfeeding cannot be reported; that is, infants predominantly breastfed cannot be distinguished from those exclusively breastfed. However, rates of 'full breastfeeding', are reported. A set of 'interim' breastfeeding indicators (Box 1, below) was developed for the NSW Child Health Survey 2001 and these incorporate the nationally recommended breastfeeding indicators where possible. Several indicators are reported for infants at four months and six months of age. This takes into account the recent change in recommendations by the NHMRC, which previously advised exclusive breastfeeding to, and introduction of solids at, four to six months and now recommends extending exclusive breastfeeding to around six months. ${ }^{8,9}$

Indicators were calculated using a survival analysis, the Kaplan-Meier method. Indicators were determined for selected population groups based on mothers' characteristics: age, education level, index of social and economic disadvantage, country of birth, English-speaking background/non-English-speaking background, indigenous status and place of residence (urban/rural). Indicators were also calculated for the population in each area health service.

A comprehensive description of the survey methods and analysis is provided in the full reports., ${ }^{3,10}$

\section{RESULTS}

Data for each of the interim indicators for NSW are pre- 
BOX 1

\section{INTERIM BREASTFEEDING INDICATORS FOR NSW DEVELOPED FOR THE NSW CHILD HEALTH SURVEY 2001}

Among all infants and children $\mathbf{0}-\mathbf{2}$ years:

1. Percentage 'ever breastfed'; ie, received breastmilk at least once

2. Percentage breastfed at each completed month of age to 12 months

3. Percentage regularly* given solid foods before four months and before six months

4. Percentage regularly ${ }^{\star}$ given breastmilk substitutes before four months and before six months

5A.Percentage fully breastfed to at least four months and six months

Among infants and children up to two years who were 'ever breastfed':

5B.Percentage fully breastfed to at least four months and six months

6. Median duration of breastfeeding

* 'Regularly' was defined as 'at least once daily'

Source: Adapted from Webb et al, 2001 'Towards a national system for monitoring breastfeeding in Australia: recommendations for population indicators, definitions and next steps' (see Box 1, page 38, and the report on the $\mathrm{CD}$ accompanying this special issue of the Bulletin) sented in Table 1, including comparisons where possible with the 1995 National Health Survey. ${ }^{6,7}$ Findings from the 2001 NSW survey and comparisons with the 1995 survey are summarised below.

Breastfeeding initiation rates in NSW were high in 2001 and appear to have increased since 1995 (Table 1, Figure 1). The percentage of NSW infants 'ever breastfed' was 90.2 per cent in 2001, higher than in many western countries (eg Ireland 34 per cent in $2000^{11}$, UK 69 per cent in $2000^{11,}$ USA 71 per cent in $2003^{12}$ ) although lower than those rates achieved in Norway and Sweden (97 to 99 per cent). ${ }^{13}$ While there was no comparable estimate of 'ever breastfed' from the 1995 National Health Survey, the percentage of NSW infants who were breastfeeding at discharge from hospital in 1995 was 78.4 per cent, and had increased by nearly 10 per cent in $2001 .^{10}$

In 2001 there was a steady decline in breastfeeding of NSW infants over the first year of life (Figure 1), such that the duration of breastfeeding was considerably shorter than recommended. This was also the case in 1995 (see Table 1). In both 1995 and 2001, about 60 per cent of infants were breastfed until at least three months of age, and 40 per cent were breastfed to six months of age. Less than 20 per cent of infants were still receiving some breastmilk at 12 months of age in 2001; this is similar to the estimated percentage for Australian infants in 1995.

TABLE 1

INDICATORS OF BREASTFEEDING PRACTICES IN NSW, 1995 AND 2001

\begin{tabular}{|c|c|c|c|}
\hline \multirow[t]{2}{*}{ Indicator } & $\begin{array}{l}\text { NSW Child Health } \\
\text { Survey } 2001\end{array}$ & \multicolumn{2}{|c|}{ National Health Survey 1995} \\
\hline & per cent & $\begin{array}{l}\text { NSW sample } \\
\text { per cent }\end{array}$ & $\begin{array}{l}\text { Australia } \\
\text { per cent }\end{array}$ \\
\hline 1. Children ever breastfed & $90.2 \quad(86.5)^{\dagger}$ & $78.4^{\dagger}$ & $81.8^{*}$ \\
\hline \multicolumn{4}{|c|}{ 2. Children breastfed to at least: } \\
\hline $\begin{array}{l}3 \text { months } \\
4 \text { months } \\
6 \text { months } \\
12 \text { months }\end{array}$ & $\begin{array}{l}61.1 \\
54.2 \\
42.5 \\
18.1\end{array}$ & $\begin{array}{r}60.0 \\
- \\
44.2 \\
-\end{array}$ & $\begin{array}{l}62.6 \\
46.2 \\
21.2\end{array}$ \\
\hline \multicolumn{4}{|c|}{ 3. Children regularly given solid food } \\
\hline $\begin{array}{l}\text { before } 4 \text { months } \\
\text { before } 6 \text { months }\end{array}$ & $\begin{array}{l}12.6 \\
69.8\end{array}$ & $\begin{array}{l}- \\
-\end{array}$ & $\overline{61.5^{\ddagger}}$ \\
\hline \multicolumn{4}{|c|}{ 4. Children regularly given breastmilk substitutes } \\
\hline $\begin{array}{l}\text { before } 4 \text { months } \\
\text { before } 6 \text { months }\end{array}$ & $\begin{array}{l}46.5 \\
59.6\end{array}$ & - & $56.9^{*}$ \\
\hline \multicolumn{4}{|c|}{ 5A. Children fully breastfed to at least: } \\
\hline $\begin{array}{l}3 \text { months } \\
4 \text { months } \\
6 \text { months }\end{array}$ & $\begin{array}{r}48.4 \\
24.6 \\
4.6\end{array}$ & $\begin{array}{r}56.6 \\
- \\
17.2\end{array}$ & $\begin{array}{c}- \\
57.1 \\
18.6\end{array}$ \\
\hline
\end{tabular}

Sources: New South Wales Child Health Survey $2001\left(\right.$ HOIST) ${ }^{3}$ Donath \& Amir ${ }^{6,7}$

* infant formula only. Does not include cow's milk or other breastmilk substitutes

$\dagger$ at hospital discharge

¥Donath \& Amir ${ }^{8}$ found nearly a $20 \%$ difference in the percent receiving solid foods reported by parents with older children at the time of the survey compared with parents of younger children, suggesting a greater error in recall among those parents who had to recall over a longer period. 


\section{FIGURE 1}

PREVALENCE OF 'ANY BREASTFEEDING' AMONG CHILDREN UP TO 12 MONTHS OF AGE, NSW 2001

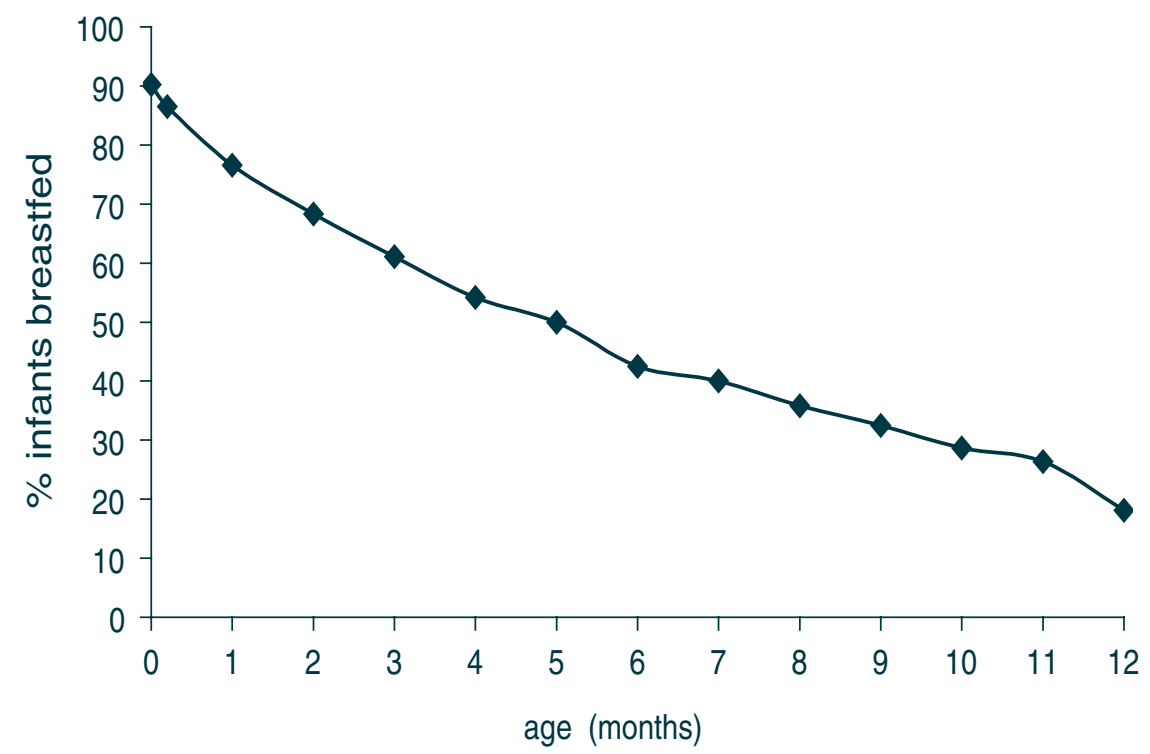

Source: Hector et al, $2001^{10}$

Rates of full breastfeeding were low in 2001 and appear to have declined since 1995. The percentage of NSW infants fully breastfed to six months was low in 1995 (17 per cent), and considerably lower in 2001 (5 per cent). This is consistent with the data showing that a substantial percentage of mothers introduce breastmilk substitutes and solid foods before the recommended six months. In 2001, 70 per cent of NSW infants were given solid foods before six months, compared with 62 per cent in 1995. In 2001, approximately 60 per cent of NSW infants were receiving breastmilk substitutes by six months, similar to the Australian estimate for 1995 .

Table 2 shows the prevalence of 'ever breastfed' and 'any breastfeeding' among infants at four, six and 12 months for selected NSW population subgroups.

In 2001, rates of initiation and duration of breastfeeding were notably lower among several population subgroups than in the NSW population as a whole. These subgroups included mothers who were younger (under 25 years), had less education, were most socioeconomically disadvantaged, or of Aboriginal or Torres Strait Islander descent. These groups also had lower rates of full breastfeeding and higher rates of early introduction of solid foods and breastmilk substitutes. ${ }^{10}$

\section{DISCUSSION}

The NSW Child Health Survey 2001 data provide a baseline against which future measurements of trends in breastfeeding practices can be compared.
There are no data describing long-term trends in breastfeeding practices for NSW and Australia, so the context of our results is unclear. However, there are some indications from comparable or similar data collected in the 1995 $5^{5-7}$ and $2001^{14}$ National Health Surveys that the observations in NSW are consistent with recent national trends. Rates of initiation of breastfeeding are high and duration of breastfeeding is considerably shorter than recommended by the NHMRC. These practices have not changed appreciably since 1995. Rates of full breastfeeding are low and probably decreasing because of the earlier introduction of solid foods and breastmilk substitutes to infants.

Data presented here indicate that NSW women are initiating breastfeeding, and most give infants at least some breastmilk until the infants are about three months old. However, most mothers do not breastfeed exclusively or fully, as they introduce solid foods and breastmilk substitutes too early. Consequently, health services development and health promotion efforts should focus on encouraging mothers to breastfeed for longer without using other foods and fluids.

The findings show a significant departure from the NHMRC recommendations on breastfeeding practices among all the women surveyed, but especially among mothers who are very young, less educated, particularly socioeconomically disadvantaged, or of Aboriginal descent. Our findings regarding these vulnerable population subgroups are consistent with those of many previous studies ${ }^{15-21}$ and suggest the need for interventions for these groups over and above efforts to improve rates in the whole 
population. Some variation in breastfeeding rates was seen between different area health services in NSW (data not shown), but these differences were generally smaller. Thus, all areas in NSW are faced with the challenge of improving breastfeeding practices.

These data from the NSW 2001 Child Health Survey have limitations. They are not strictly comparable with the National Health Survey estimates because of differences in sampling, some of the survey questions and methods of calculating indicators. Further, the size of NSW survey samples of vulnerable population subgroups and local area health service populations is small, limiting statistical power and confidence in the magnitude of observed differences. The adoption of standardised methods for monitoring breastfeeding by state telephone surveys and the ABS National Health Survey program would enable us to document trends and population differences in breastfeeding practices. The questions used in the NSW Child Health Survey 2001 did not permit all of these indicators to be reported. ${ }^{3}$ A number of new questions relating to breastfeeding practices have therefore been recommended for ongoing surveys in NSW. The NSW Health Survey Program also plans to increase the sample size of population subgroups and local area health services through continuous, rather than periodic, data collection methods.

Many factors are likely to contribute to less than optimal infant feeding practices, including those outlined by Hector et al in the paper 'Factors affecting breastfeeding practices' in this issue. Concerted and sustained public health interventions are required that focus on encouraging exclusive breastfeeding during the early months and an extended duration of breastfeeding to at least the recommended 12 months.

\section{ACKNOWLEDGMENTS}

Sharyn Lymer was a trainee on the NSW Biostatistical Officer Training Program when she worked on this paper.

Report on breastfeeding in NSW 2004 is included on the CD that accompanies this special issue of the NSW Public Health Bulletin. It is also available at www.health.nsw.gov.au/public-health/health-promotion/nutrition/breastfeeding/index.html and www. cphn.biochem.usyd.edu.au/resources/index.html

\section{TABLE 2}

PREVALENCE OF 'EVER BREASTFED’ AND ANY BREASTFEEDING AMONG INFANTS TO 4 MONTHS, 6 MONTHS AND 12 MONTHS, BY POPULATION SUB-GROUPS, NSW 2001

\begin{tabular}{|c|c|c|c|c|}
\hline \multirow[t]{2}{*}{ Population characteristics of mothers } & \multirow[t]{2}{*}{$\begin{array}{l}\text { 'ever breastfed' } \\
\text { per cent }\end{array}$} & \multicolumn{3}{|c|}{$\begin{array}{l}\text { 'any breastfeding' to at least this age } \\
\text { per cent }\end{array}$} \\
\hline & & 4 months & 6 months & 12 months \\
\hline \multicolumn{5}{|l|}{ Age } \\
\hline$<25$ yrs & 84.5 & 34.9 & 27.1 & 8.4 \\
\hline$\geq 25$ yrs & 90.4 & 56.5 & 44.5 & 20.9 \\
\hline \multicolumn{5}{|l|}{ Education } \\
\hline Primary/secondary & 86.8 & 44.5 & 33.5 & 15.0 \\
\hline Tertiary & 96.1 & 71.4 & 58.6 & 23.6 \\
\hline \multicolumn{5}{|l|}{ SEIFA* } \\
\hline $1^{\text {st }}$ quintile (least disadvantaged) & 95.5 & 64.2 & 55.4 & 26.9 \\
\hline $2^{\text {nd }}$ quintile & 89.8 & 57.2 & 45.6 & 17.8 \\
\hline $3^{\text {rd }}$ quintile & 87.3 & 52.0 & 36.9 & 13.7 \\
\hline $4^{\text {th }}$ quintile & 92.4 & 46.8 & 35.9 & 17.2 \\
\hline $5^{\text {th }}$ quintile (most disadvantaged) & 86.2 & 50.0 & 37.2 & 14.3 \\
\hline \multicolumn{5}{|l|}{ Country of birth } \\
\hline Australia & 90.4 & 53.3 & 41.8 & 16.2 \\
\hline Overseas & 88.0 & 56.2 & 44.7 & 24.6 \\
\hline \multicolumn{5}{|l|}{ Language spoken at home } \\
\hline English-speaking & 90.9 & 54.4 & 43.0 & 18.2 \\
\hline Non-English-speaking & 87.9 & 53.4 & 40.6 & 17.8 \\
\hline \multicolumn{5}{|l|}{ Indigenous status } \\
\hline Aboriginal and Torres Strait Islander & 72.4 & $31.3^{* *}$ & 22.2 & 10.0 \\
\hline Not Aboriginal or Torres Strait Islander & 90.6 & 54.6 & 43.0 & 18.4 \\
\hline \multicolumn{5}{|l|}{ Place of residence } \\
\hline Urban & 89.8 & 53.1 & 40.7 & 17.3 \\
\hline Rural & 91.4 & 58.4 & 48.9 & 21.5 \\
\hline
\end{tabular}




\section{REFERENCES}

1. National Health and Medical Research Council. Dietary guidelines for children and adolescents in Australiaincorporating the infant feeding guidelines for health workers. Canberra: Commonwealth of Australia, 2003. Available at www.nhmrc.gov.au/publications/pdf/n34.pdf, accessed 2 June 2005.

2. Webb K, Marks GC, Lund-Adams M, Rutishauser IHE, Abraham B. Towards a national system for monitoring breastfeeding in Australia: recommendations for population indicators, definitions and next steps. Canberra: Australian Food and Nutrition Monitoring Unit, Commonwealth Department of Health and Aged Care; 2001. Available on the CD distributed with this issue of the Bulletin and at www. health.nsw.gov.au/public-health/phb/phb.html.

3. Centre for Epidemiology and Research, NSW Department of Health. New South Wales child health survey 2001. N S W Public Health Bull 2002: 13(S-4). Available at www.health.nsw.gov. au/public-health/phb/NSWChildHealthSurvey2001.pdf.

4. Stickney B, Webb KL, Campbell C, Moore AR. Food and nutrition in New South Wales: a catalogue of data. NSW Health Department, 1994.

5. Australian Bureau of Statistics. National Health Survey: users' guide 1995. ABS Catalogue Number 4363.0. Canberra: ABS, 1996.

6. Donath SM, Amir LH. Rates of breastfeeding in Australia by state and socio-economic status: evidence from the 1995 National Health Survey. J Pediatr Child Health 2000; 36: 164-8.

7. Donath SM, Amir LH. Introduction of breast milk substitutes and solid foods: evidence from the 1995 National Health Survey. Aust N Z J Public Health 2002; 26(5): 481-4.

8. National Health and Medical Research Council. Dietary guidelines for children and adolescents. Canberra: Commonwealth of Australia, 1995.

9. National Health and Medical Research Council. Infant feeding guidelines for health workers. Canberra: Commonwealth of Australia, 1996.
10. Hector D, Webb K, Lymer S. State of food and nutrition in NSW series: report on breastfeeding in NSW. Sydney: NSW Department of Health; 2004 (revised 2005).

11. Hamlyn B, Brooker S, Oleinikova K, Wands S. Infant feeding 2000. London: The Stationery Office; 2002.

12. Li R, Zhao Z, Mokdad A, Barker L, Grummer-Strawn L. Prevalence of breastfeeding in the United States: the 2001 National Immunization Survey. Pediatrics 2003; 111: 1198-201.

13. Alvarez L. Norway leads industrial nations back to breastfeeding. New York Times. October 2, 2003.

14. Australian Bureau of Statistics 4810.0.55.001 Breastfeeding in Australia. At www.abs.gov.au/Ausstats/abs@.nsf/ 0/8e65d 6253e10f802ca256da40003a07c, accessed 9 June 2005.

15. Binns C. Encourage and support breastfeeding. J HEIA 2004; 11(1): 28-38.

16. Redman S, Booth P, Smyth H, Paul C. Preventive health behaviours among parents of infants aged four months. Aust J Public Health 1992; 16(2): 175-81.

17. Jain SK. Breastfeeding in Australia 1996 occasional paper. Canberra: Australian Bureau of Statistics. cat. no.04394.0; 1996.

18. Vogel A, Hutchison BL, Mitchell EA. Factors associated with the duration of breastfeeding. Acta Paediatr 1999; 88: 1320-6.

19. Scott JA, Binns CW. Factors associated with the initiation and duration of breastfeeding: a review of the literature. Breastfeeding Rev 1999; 7: 5-16.

20. North KP, Emmett S, Noble S, ALSPAC team. Types of drinks consumed by infants at 4 and 8 months of age: sociodemographic variations. J Nutr Diet 2000; 13(2): 71-82.

21. Dubois L, Girard M. Social determinants of initiation, duration and exclusivity of breastfeeding at the population level: the results of the Longitudinal Study of Child Development in Quebec (ELDEQ 1998-2002). Can J Public Health 2003; 94(4): 300-5. 생 